\title{
Efeito da temperatura na síntese de óxidos hidratados de nióbio e zircônio e adsorção de íons $\mathbf{A g}^{+} \mathbf{e} \mathbf{P b}^{2+}$
}

\section{(Effect of temperature on the synthesis of hydrous metallic oxides and adsorption of $\mathrm{Ag}^{+}$and $\mathrm{Pb}^{2+}$ ions)}

\author{
A. L. C. Peixoto, G. L. J. P. da Silva, M. L. C. P. da Silva \\ Departamento de Engenharia Química, Faculdade de Engenharia Química de Lorena \\ Rodovia Itajubá-Lorena, $\mathrm{km}$ 74,5, C.P. 116, Lorena, SP 12600-000 \\ mlcaetano@dequi.faenquil.br
}

\begin{abstract}
Resumo
Este trabalho mostra o efeito da temperatura de digestão do agente precipitante nas características físicas e químicas do $\mathrm{Nb}_{2} \mathrm{O}_{5} \cdot \mathrm{nH}_{2} \mathrm{O}$ e do $\mathrm{ZrO}_{2} \cdot \mathrm{nH}_{2} \mathrm{O}$. Os compostos foram obtidos pelo método da precipitação em solução homogênea com a decomposição térmica do $\left(\mathrm{NH}_{4}\right)_{2} \mathrm{CO}_{3}$ realizada a $45^{\circ} \mathrm{C}$ e a $90^{\circ} \mathrm{C}$. A difração de raios $\mathrm{X}$ mostrou que o $\mathrm{Nb}_{2} \mathrm{O}_{5} \cdot \mathrm{nH}_{2} \mathrm{O}$ preparado em qualquer uma das duas temperaturas é material cristalino apresentando espaçamento interlamelar, enquanto que o $\mathrm{ZrO}_{2} \cdot \mathrm{nH}_{2} \mathrm{O}$ é amorfo. Pela análise térmica observou-se grau de hidratação semelhante para todos os materiais. As isotermas de Langmuir revelaram que os melhores resultados de adsorção foram alcançados para ambos os materiais preparados a $90{ }^{\circ} \mathrm{C}$.

Palavras-chave: óxidos metálicos hidratados, isoterma de Langmuir, precipitação em solução homogênea.
\end{abstract}

Abstract

This work reports the digestion temperature effect of precipitating agent on the physical and chemical characteristics of $\mathrm{Nb}_{2} \mathrm{O}_{5}$. $n \mathrm{H}_{2} \mathrm{O}$ and $\mathrm{ZrO}_{2} \cdot n \mathrm{H}_{2} \mathrm{O}$. The compounds were obtained by homogeneous solution precipitation method with thermal decomposition of $\left(\mathrm{NH}_{4}\right)_{2} \mathrm{CO}_{3}$ at $45^{\circ} \mathrm{C}$ and $90{ }^{\circ} \mathrm{C}$. The $\mathrm{X}$-ray diffraction analysis showed crystalline materials with interlamelar space for both $\mathrm{Nb}_{2} \mathrm{O}_{5} \cdot n \mathrm{H}_{2} \mathrm{O}$, whereas $\mathrm{ZrO}_{2} \cdot \mathrm{nH}_{2} \mathrm{O}$ is amorphous. By thermal analysis a similar hydration grade was observed for all materials. The Langmuir adsorption isotherms show that the materials prepared at $90{ }^{\circ} \mathrm{C}$, in both cases, have the best results.

Keywords: metallic hydrated oxides, Langmuir isotherm, homogeneous solution precipitation.

\section{INTRODUÇÃO}

A aplicação de materiais no processo de troca iônica surgiu com o uso de produtos naturais como argilas, zeólitas e ácidos húmicos no tratamento de água. No entanto, o primeiro trocador iônico utilizado comercialmente foi o gel de aluminossilicato amorfo, muito embora o mesmo apresente instabilidade química diante de soluções ácidas [1]. Houve um interesse considerável na preparação e aplicação de materiais inorgânicos para troca iônica nas últimas quatro décadas, em decorrência das condições favoráveis destes materiais se comparados com as resinas orgânicas. Dentre as vantagens destes trocadores iônicos estão estabilidade em meio ácido à moderadamente alcalino, alta seletividade e resistência à altas temperaturas e radiação [2,3]. As principais classes destes materiais incluem fosfatos insolúveis, arsenatos, tungstatos, molibdatos, hexacianoferratos e óxidos hidratados de cátions multivalentes [2].

Os óxidos metálicos hidratados são trocadores iônicos que têm sido intensivamente investigados para aplicações no tratamento de efluentes nucleares. Nestes materiais, a acidez dos sítios ativos aumenta com a valência do metal.
Características como cristalinidade e teor de hidratação também têm forte efeito nas propriedades de troca iônica [4]. Diversos métodos vêm sendo utilizados para a obtenção de dispersões coloidais, objetivando um melhor controle de forma e de distribuição de tamanhos de partículas. Os principais métodos de preparação podem ser resumidamente divididos em três classes: 1) precipitação em solução homogênea, 2) transformação de fases e 3) reações com aerossóis.

O método mais utilizado é a precipitação em solução homogênea, o qual consiste em atingir a supersaturação crítica das espécies que formam a fase sólida, de modo que a formação de núcleos se faça por um processo extremamente rápido e único. $\mathrm{O}$ desenvolvimento destes núcleos ocorre posteriormente ao processo de nucleação resultando, assim, em dispersões com estreita distribuição de tamanhos e com homogeneidade de forma [5]. Na técnica de precipitação de uma solução homogênea, o reagente precipitante não é adicionado como tal, mas é gerado por meio de uma reação química cineticamente lenta e homogênea em todo o seio da solução, resultando na formação de cristais maiores e mais puros [6]. 
Em trabalho anterior do grupo, foi estudada a preparação do óxido de nióbio hidratado pelo método da precipitação em solução homogênea (PSH), utilizando uréia como precursor de precipitação a uma temperatura de $90{ }^{\circ} \mathrm{C}$ [7]. Comparouse, por fim, o óxido de nióbio hidratado preparado pelos métodos PSH e PC.

Tagliaferro et al. [8] estudaram, ainda, as variáveis de preparação do $\mathrm{Nb}_{2} \mathrm{O}_{5} \cdot \mathrm{nH}_{2} \mathrm{O}$ em PSH como: tipo de agente precipitante (uréia e carbonato de amônio), ordem de adição do agente precipitante e tempo de precipitação $(4,5$ e 8 h). O carbonato de amônio mostrou ser o agente precipitante mais indicado na preparação do $\mathrm{Nb}_{2} \mathrm{O}_{5} \cdot \mathrm{nH}_{2} \mathrm{O}$, devido à melhor eficiência de troca iônica obtida com o íon sódio para os materiais preparados com esse precursor.

A síntese de $\mathrm{ZrO}_{2} \cdot \mathrm{nH}_{2} \mathrm{O}$ por meio dos métodos $\mathrm{PC}$ e $\mathrm{PSH}$ também foi estudada pelo grupo [3]. Foram utilizados como agentes precipitantes para o método PSH o nitrito de sódio, o carbonato de amônio e a uréia. Para o método PC, usou-se o hidróxido de amônio. Todas as sínteses por PSH, foram realizadas a $90{ }^{\circ} \mathrm{C}$, que é a temperatura de decomposição da uréia $[3,7-9]$.

O objetivo do presente trabalho é verificar a influência da temperatura sobre as características físicas (cristalinidade e grau de hidratação) e, principalmente químicas (Capacidade de Troca Iônica, CTI), dos óxidos $\mathrm{ZrO}_{2} \cdot \mathrm{nH}_{2} \mathrm{O}$ e $\mathrm{Nb}_{2} \mathrm{O}_{5} \cdot n \mathrm{H}_{2} \mathrm{O}$ obtidos pelo método PSH. Foi empregado carbonato de amônio como gerador de hidroxilas (agente precipitante). Por fim, verificou-se a melhor rota para a preparação dos materiais para aplicação em troca catiônica. Dessa forma, a preparação dos óxidos metálicos foi realizada a $45^{\circ} \mathrm{C}$, que é a temperatura de decomposição do carbonato de amônio e $90{ }^{\circ} \mathrm{C}$ como temperatura de referência até então utilizada em trabalhos anteriores do grupo.

\section{EXPERIMENTAL}

\section{Preparação dos óxidos hidratados de nióbio e zircônio}

Na precipitação em solução homogênea (PSH), o óxido de nióbio (V) hidratado foi obtido pela dissolução do $\mathrm{Nb}$ (produto da $4^{\mathrm{a}}$ fusão, produzido no Departamento de Materiais da FAENQUIL) a uma mistura ácida de $\mathrm{HNO}_{3}$ $(65 \%)$ / HF (40\%) na relação 1:3 molar. Depois de todo o material solubilizado, adicionou-se o ácido bórico $(20,0 \mathrm{~g})$ e o precursor do agente precipitante $(92,0 \mathrm{~g}$ de carbonato de amônio), gerando in situ as hidroxilas pela decomposição térmica do mesmo. A reação foi conduzida com aquecimento de $45{ }^{\circ} \mathrm{C}$. O precipitado foi filtrado, lavado com água deionizada e secado a $50{ }^{\circ} \mathrm{C}$ em estufa. Um novo material foi preparado, segundo procedimento descrito, modificando apenas a temperatura do meio reacional para $90{ }^{\circ} \mathrm{C}$.

$\mathrm{O}$ óxido de zircônio hidratado foi obtido pela dissolução de 5,0 g de $\mathrm{ZrOCl}_{2} .8 \mathrm{H}_{2} \mathrm{O}$ em $\mathrm{HCl} 0,5 \mathrm{~mol} \mathrm{~L}^{-1}$. Depois de todo o material solubilizado, adicionou-se o precursor do agente precipitante (40,0 g de carbonato de amônio), gerando in situ as hidroxilas pela decomposição térmica do mesmo. A reação foi conduzida com aquecimento de $45^{\circ} \mathrm{C}$.
O precipitado foi filtrado, lavado com água deionizada e secado a $50{ }^{\circ} \mathrm{C}$ em estufa. Um novo material foi preparado, segundo o procedimento descrito, modificando apenas a temperatura do meio reacional para $90^{\circ} \mathrm{C}$.

\section{Caracterização}

Os óxidos metálicos hidratados preparados foram caracterizados por difração de raios X (XRD). Os difratogramas foram obtidos em difratômetro RICH SEIFERT com fonte de radiação $\mathrm{Cuk}_{\alpha}, 30 \mathrm{kV}, 40 \mathrm{~mA}$. A varredura foi feita com passo de $0,05^{\circ}$ variando-se $2 \theta$ entre 10 e $70^{\circ}$. Os difratogramas obtidos foram identificados a partir de padrões JCPDS.

A análise por termogravimetria (TG/DTG) foi obtida em uma termobalança Shimadzu, modelo TGA-50, com razão de aquecimento de $20{ }^{\circ} \mathrm{C} \mathrm{min}-1$ em fluxo de nitrogênio. A faixa de temperaturas analisadas foi entre $25^{\circ} \mathrm{C}$ e $900{ }^{\circ} \mathrm{C}$.

\section{Estudo da adsorção dos íons $\mathrm{Ag}^{+}$e $\mathrm{Pb}^{2+}$ pelo modelo de Langmuir}

Neste estudo, $50,0 \mathrm{~mL}$ da solução salina de $\mathrm{AgNO}_{3}$ foram colocados em contato com $0,1 \mathrm{~g}$ do óxido metálico preparado, mantendo-se sob agitação constante. Para os óxidos de nióbio preparados a $45^{\circ} \mathrm{C}$ e a $90^{\circ} \mathrm{C}$, foram necessárias $6 \mathrm{~h}$ de agitação [8], enquanto, os óxidos de zircônio a $45^{\circ} \mathrm{C}$ e a $90{ }^{\circ} \mathrm{C}$ foram agitados por $40 \mathrm{~min}$ [3].

Para determinar as concentrações iniciais e finais (ou de equilíbrio, $\left.C_{e}\right)$ de $\mathrm{Ag}^{+}$, utilizou-se um espectrofotômetro de absorção atômica Varian modelo AA-1475. Utilizou-se o modelo linear segundo Langmuir com os resultados obtidos para descrever o processo de remoção dos íons [10].

Para o estudo de adsorção do íon $\mathrm{Pb}^{2+}$ utilizou-se o mesmo procedimento descrito acima, por meio da solução salina de $\mathrm{Pb}\left(\mathrm{NO}_{3}\right)_{2}$.

\section{RESULTADOS E DISCUSSÃO}

Foram sintetizados óxidos metálicos hidratados com elevação gradual da temperatura após a adição do carbonato de amônio. Assim, a precipitação dos materiais preparados a $90{ }^{\circ} \mathrm{C}$ ocorreu lentamente, como é esperado pela precipitação em solução homogênea. Realizaram-se sínteses a $45^{\circ} \mathrm{C}$ uma vez que essa é a temperatura de decomposição térmica do carbonato de amônio, proporcionando precipitação ainda mais lenta e gradual dos óxidos.

Em trabalhos anteriores realizados em nosso grupo [3, 7 9], foi observado que a presença do ácido fluorídrico no meio reacional não permite a formação do precipitado. Dessa forma, para a preparação dos óxidos de nióbio hidratados adicionouse ácido bórico. A presença de íons fluoreto gera complexos boro-flúor, o que elimina o excesso de fluoreto existente na solução, ocasionando, assim, a geração do precipitado desejado [11]. Houve a elevação do $\mathrm{pH}$ da solução ácida com a decomposição térmica do carbonato de amônio, permitindo a lenta e gradual formação dos óxidos metálicos hidratados 
pela geração das espécies hidroxilas [8].

A Fig. 1 mostra os difratogramas de raios $\mathrm{X}$ dos óxidos de nióbio (V) e de zircônio hidratados. Verifica-se que os óxidos de nióbio (V) hidratado apresenta picos definidos juntamente com áreas amorfas. Observa-se, também, difração abaixo de $20^{\circ}$. A literatura apresenta uma variedade de trabalhos cujos materiais inorgânicos apresentam picos de difração nesta região [1, 1214]. Esses picos são decorrentes das distâncias entre as lamelas, sendo possível a utilização desses materiais em processos de troca iônica, intercalação e pilarização $[15,16]$. Assim, por meio dos picos de maior intensidade dos difratogramas $\left(2 \theta<20^{\circ}\right)$, foi possível quantificar o espaçamento lamelar dos óxidos de nióbio hidratados. Verificou-se que o $\mathrm{Nb}_{2} \mathrm{O}_{5} \cdot \mathrm{nH}_{2} \mathrm{O}$ preparado a $45^{\circ} \mathrm{C}$ possui espaçamento lamelar de $6,097 \AA$ e que o $\mathrm{Nb}_{2} \mathrm{O}_{5} \cdot \mathrm{nH}_{2} \mathrm{O}$ preparado a $90^{\circ} \mathrm{C}$ possui $6,131 \AA$. A Fig. 1 mostra, ainda, que os óxidos de zircônio hidratados preparados a $45^{\circ} \mathrm{C}$ e a $90^{\circ} \mathrm{C}$ não apresentam picos definidos, revelando seu caráter amorfo.

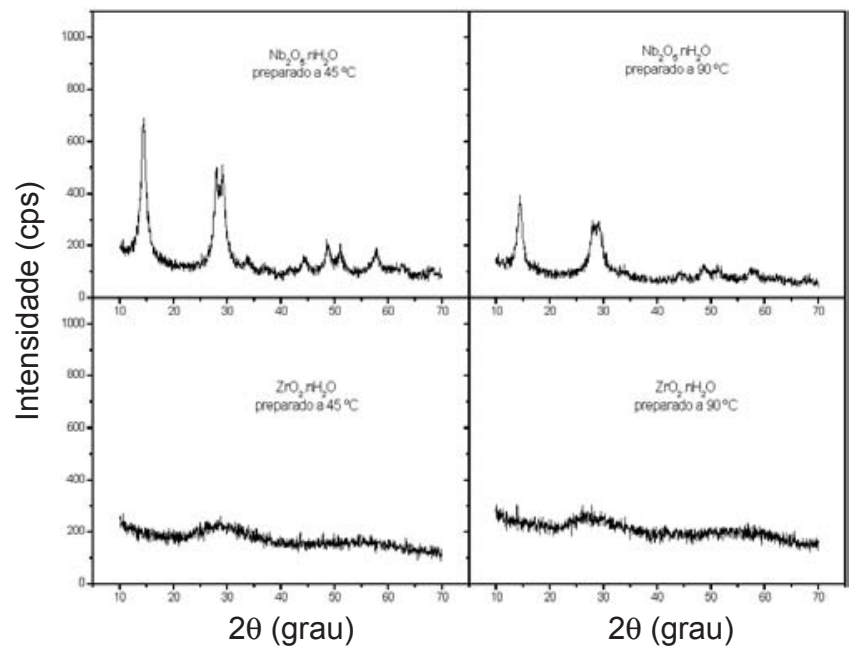

Figura 1: Difratogramas de raios $\mathrm{X}$ dos óxidos de nióbio e de zircônio hidratados preparados a $45^{\circ} \mathrm{C}$ e a $90^{\circ} \mathrm{C}$.

[Figure 1: X-ray diffraction patterns of hydrous niobium and zirconium oxides prepared at $45^{\circ} \mathrm{C}$ and $90^{\circ} \mathrm{C}$.]

O óxido de nióbio hidratado obtido pelo método PC apresentou maior cristalinidade, obtendo-se melhor capacidade de troca iônica com o íon sódio, se comparado com o material amorfo obtido pelo método PSH [7]. Isso demonstrou que o grau de cristalinidade influencia na capacidade de troca iônica do óxido de nióbio (V) hidratado. $\mathrm{O}$ mesmo foi observado no estudo do ácido túngstico $\left(\mathrm{WO}_{3}\right.$. $\mathrm{nH}_{2} \mathrm{O}$ ), o de maior grau de cristalinidade apresentou também maior capacidade de troca iônica com íon sódio [17].

Com os resultados dos difratogramas dos óxidos de nióbio e de zircônio hidratados, tentou-se compará-los com o padrão JCPDS. Verificou-se a não existência de ficha para esses óxidos nas formas hidratadas. Dessa forma, fez-se o tratamento térmico em todos os materiais a $550{ }^{\circ} \mathrm{C}$ por $6 \mathrm{~h}$, obtendo-se, assim, os óxidos metálicos na sua forma anidra. Os difratogramas de raios $\mathrm{X}$ dos materiais tratados termicamente estão na Fig. 2. As novas distâncias interplanares calculadas nos materiais tratados termicamente correspondem ao óxido de nióbio (JCPDS 27-
1003) e de zircônio (JCPDS 37-1413) anidros. Os difratogramas de raios $\mathrm{X}$ dos óxidos de zircônio calcinados (Fig. 2) mostram reflexões de fase não identificada em $28,15^{\circ}(\mathrm{d}=3,170 \AA)$ e em $31,30^{\circ}(\mathrm{d}=2,858 \AA)$.

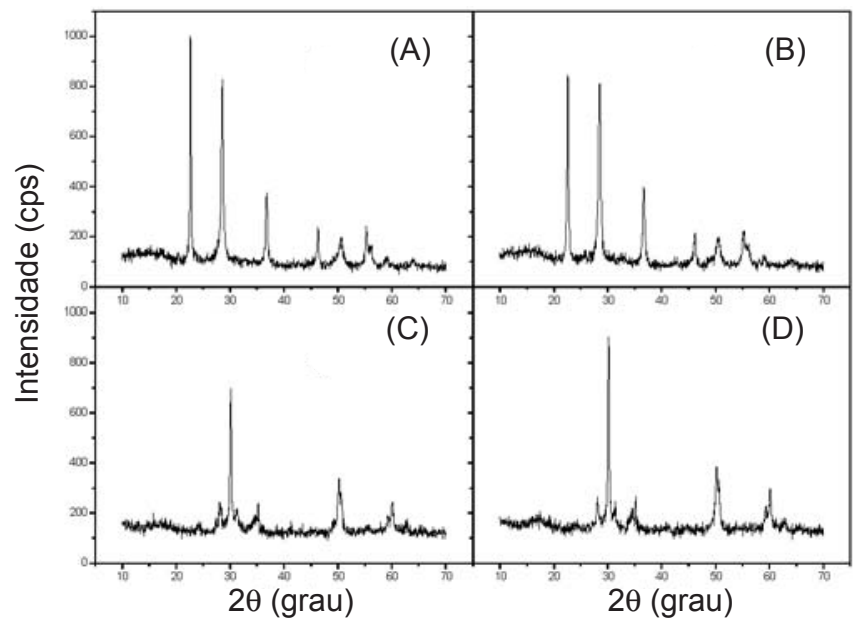

Figura 2: Difratogramas de raios $\mathrm{X}$ dos óxidos de nióbio hidratados preparados a $45^{\circ} \mathrm{C}(\mathrm{A})$ e a $90^{\circ} \mathrm{C}(\mathrm{B})$, dos óxidos de zircônio hidratados preparados a $45^{\circ} \mathrm{C}(\mathrm{C})$ e a $90^{\circ} \mathrm{C}(\mathrm{D})$ e calcinados a $550{ }^{\circ} \mathrm{C}$.

[Figure 2: X-ray diffraction patterns of hydrous niobium oxides prepared at $45{ }^{\circ} \mathrm{C}(\mathrm{A})$ and $90{ }^{\circ} \mathrm{C}(\mathrm{B})$, and of hydrous zirconium oxides prepared at $45^{\circ} \mathrm{C}(\mathrm{C})$ and $90^{\circ} \mathrm{C}(\mathrm{D})$ and calcinated at $550^{\circ} \mathrm{C}$.]

A análise termogravimétrica foi utilizada para determinar o grau de hidratação $\mathbf{n}$ e a estabilidade térmica dos óxidos preparados. Esse estudo é importante porque o grau de hidratação corresponde aos sítios ativos de troca iônica e conseqüentemente podem influenciar na sua capacidade de troca iônica $[19,20]$.

A Fig. 3 mostra as curvas de análise térmica dos óxidos metálicos hidratados sintetizados. As curvas de análise térmica dos óxidos de nióbio hidratados (Figs. 3A e 3B) apresentam perda de massa em duas etapas distintas na faixa de 25 a $600{ }^{\circ} \mathrm{C}$. Na primeira etapa $\left(25\right.$ a $\left.300^{\circ} \mathrm{C}\right)$ houve perda de massa devido à eliminação de águas ligadas quimicamente ao óxido. Na segunda etapa $\left(300\right.$ a $\left.600^{\circ} \mathrm{C}\right)$ houve eliminação de água devido à condensação dos grupos hidroxilas ligados à matriz do trocador [9]. As curvas de análise térmica dos óxidos de zircônio hidratados (Figs. 3C e 3D) também apresentaram perda de massa ocorrendo em duas etapas distintas, entre 25 e $600{ }^{\circ} \mathrm{C}$. Na primeira etapa, entre 25 e $300{ }^{\circ} \mathrm{C}$, ocorreu perda de moléculas de água fracamente ligadas à matriz. $\mathrm{Na}$ segunda etapa, de 300 a $600{ }^{\circ} \mathrm{C}$, ocorreram perdas de massa de $7,9 \%$ para o óxido preparado a $45{ }^{\circ} \mathrm{C}$ e de $3,7 \%$ para o material preparado a $90{ }^{\circ} \mathrm{C}$. Ambas podem ser atribuídas a resíduos de carbonato presentes nas matrizes [3]. Os óxidos de zircônio hidratados preparados a partir de uréia e nitrito de sódio, como geradores de hidroxilas (agente precipitante) apresentam perda de massa em uma única etapa [3]. A presença de resíduos também pode ser confirmada pelas reflexões extras encontradas para os óxidos de zircônio calcinados (Fig. 2).

A fórmula estequiométrica de cada óxido preparado pode 

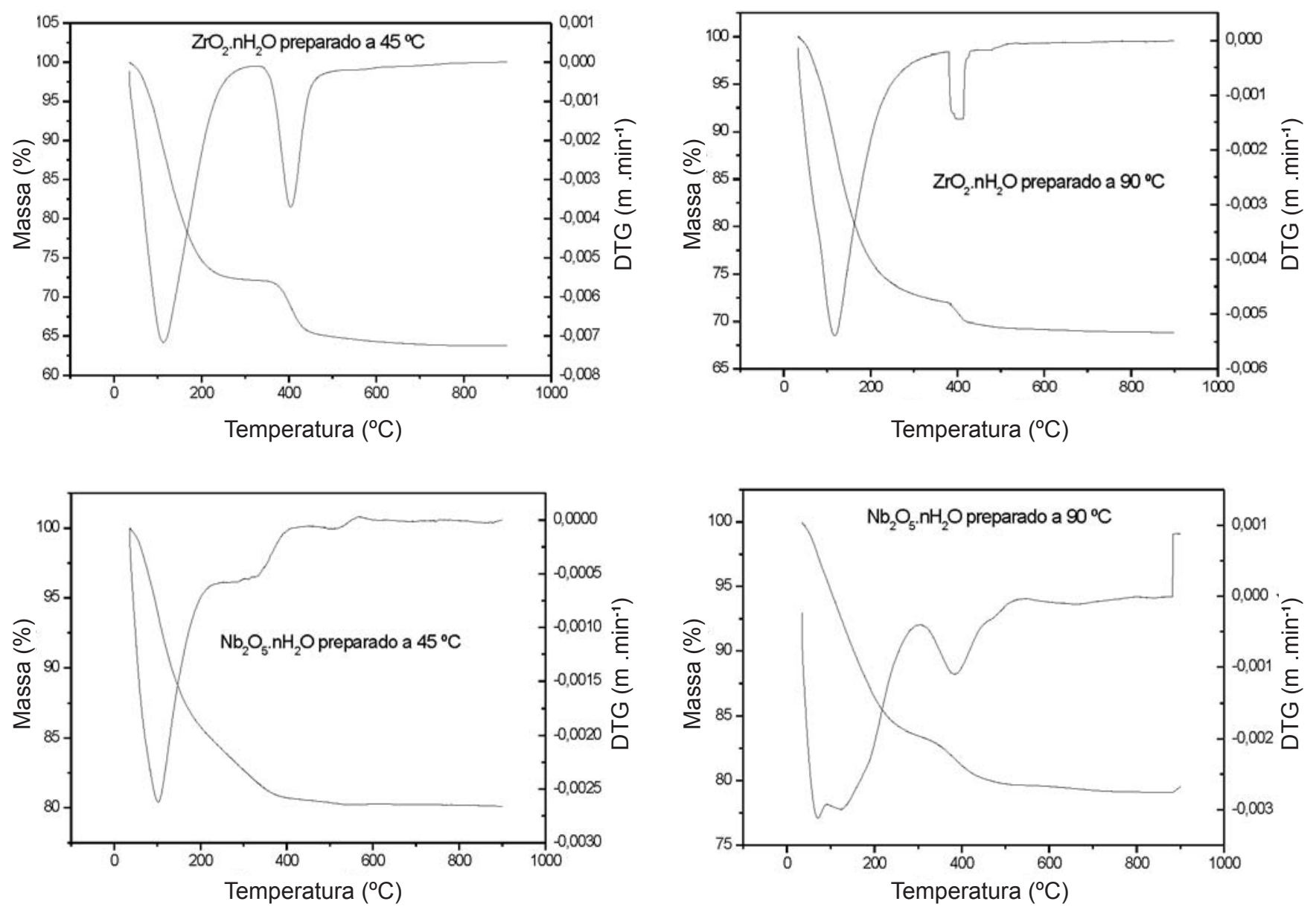

Figura 3: Curvas TG/DTG do $\mathrm{Nb}_{2} \mathrm{O}_{5} \cdot \mathrm{nH}_{2} \mathrm{O}$ e do $\mathrm{ZrO}_{2} \cdot \mathrm{nH}_{2} \mathrm{O}$.

[Figure 3: TG/DTG curves of $\mathrm{Nb}_{2} \mathrm{O}_{5} \cdot n \mathrm{H}_{2} \mathrm{O}$ and $\mathrm{ZrO}_{2} \cdot n \mathrm{H}_{2} \mathrm{O}$.]

Tabela I - Parâmetros obtidos das curvas termogravimétricas (TG) para os materiais preparados (PR) a diferentes temperaturas. Perda de massa nas curvas DTG (dM) nos respectivos intervalos de temperatura $(\Delta \mathrm{T})$, perda de massa na curva TG (M) e respectivos graus de hidratação (n).

[Table I - Results of TG/DTG curves obtained for preparations $(P R)$, with the correspondent temperatures at mass loss in DTG curves $(d M)$, in the respective temperature range $(\Delta T)$, mass loss in TG curves (M) and respective hydration grade (n).]

\begin{tabular}{ccccc}
\hline $\mathrm{PR}$ & $\mathrm{dM}\left({ }^{\circ} \mathrm{C}\right)$ & $\Delta \mathrm{T}\left({ }^{\circ} \mathrm{C}\right)$ & $\mathrm{M}(\%)$ & $\mathrm{n}$ \\
\hline $\mathrm{ZrO}_{2} \cdot \mathrm{nH}_{2} \mathrm{O}$ & 113,0 & $25-300$ & 27,5 & 3,8 \\
$\left(45^{\circ} \mathrm{C}\right)$ & 404,2 & $300-600$ & 7,9 & \\
$\mathrm{ZrO}_{2} \cdot \mathrm{nH}_{2} \mathrm{O}$ & 118,2 & $25-300$ & 26,9 & 3,0 \\
$\left(90^{\circ} \mathrm{C}\right)$ & 408,8 & $300-600$ & 3,7 & \\
$\mathrm{Nb}_{2} \mathrm{O}_{5} \cdot \mathrm{nH}_{2} \mathrm{O}$ & 100,8 & $25-250$ & 15,9 & 3,6 \\
$\left(45^{\circ} \mathrm{C}\right)$ & & $250-600$ & 3,6 & \\
$\mathrm{Nb}_{2} \mathrm{O}_{5} \cdot \mathrm{nH}_{2} \mathrm{O}$ & 71,0 & $25-300$ & 16,4 & 3,7 \\
$\left(90^{\circ} \mathrm{C}\right)$ & 382,5 & $300-600$ & 3,8 & \\
\hline
\end{tabular}

ser determinada considerando-se a perda total de água apresentada por termogravimetria (TG), nos intervalos de temperatura de $25^{\circ} \mathrm{C}$ a $600{ }^{\circ} \mathrm{C}$. Efetuaram-se os cálculos [9], obtendo-se o grau de hidratação para cada material preparado $\mathrm{e}$, conseqüentemente, suas fórmulas estequiométricas. Estes resultados encontram-se na Tabela I, juntamente com os dados obtidos pelas curvas de análise térmica (Fig. 3).

Os resultados da Tabela I mostram que o material com maior grau de hidratação é o óxido de zircônio preparado a $45^{\circ} \mathrm{C}$, com $n$ igual a 3,8 . Percebe-se que há uma diferença significativa no grau de hidratação do óxido de zircônio em função da temperatura de síntese. Para os óxidos de nióbio, observou-se resultado semelhante ao do $\mathrm{ZrO}_{2} \cdot \mathrm{nH}_{2} \mathrm{O}\left(45^{\circ} \mathrm{C}\right)$. Teoricamente, quanto maior o grau de hidratação maior o número de sítios para troca iônica e, consequentemente, maior a CTI. Mas existem outros fatores que também influenciam no valor de CTI, tais como cristalinidade e presença de lamelas [9].

Estudou-se a remoção dos íons $\mathrm{Ag}^{+}$e $\mathrm{Pb}^{2+}$ pelos óxidos de nióbio (V) e de zircônio hidratados sintetizados a $45^{\circ} \mathrm{C}$ e a $90{ }^{\circ} \mathrm{C}$, conforme Figs. 4 e 5. Neste estudo, segundo o modelo de Langmuir, caracterizam-se a capacidade e os parâmetros de adsorção do material adsorvente por meio da região 

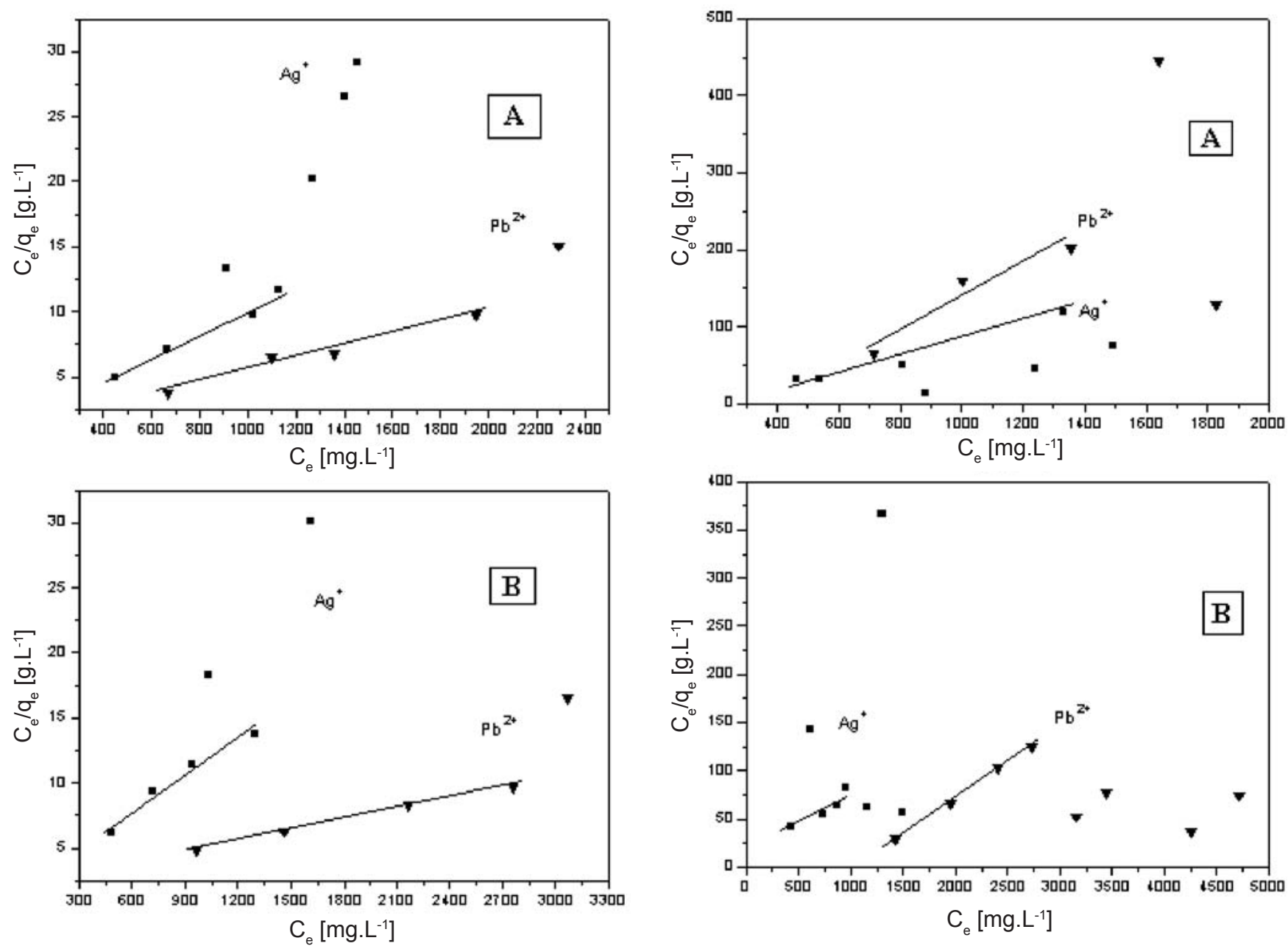

Figura 4: Isotermas de adsorção de Langmuir para $\mathrm{Ag}^{+}$e $\mathrm{Pb}^{2+}$ utilizando $\mathrm{Nb}_{2} \mathrm{O}_{5} \cdot \mathrm{nH}_{2} \mathrm{O}$ preparado a $45^{\circ} \mathrm{C}(\mathrm{A})$ e a $90{ }^{\circ} \mathrm{C}(\mathrm{B})$.

[Figure 4: Langmuir adsorption isotherms for $\mathrm{Ag}^{+}$and $\mathrm{Pb}^{2+}$ using $\mathrm{Nb}_{2} \mathrm{O}_{5} . n \mathrm{H}_{2} \mathrm{O}$ prepared at $45^{\circ} \mathrm{C}(\mathrm{A})$ and $90{ }^{\circ} \mathrm{C}(\mathrm{B})$.]

Figura 5: Isotermas de adsorção de Langmuir para $\mathrm{Ag}^{+}$e $\mathrm{Pb}^{2+}$ utilizando $\mathrm{ZrO}_{2} \cdot \mathrm{nH}_{2} \mathrm{O}$ preparado a $45^{\circ} \mathrm{C}(\mathrm{A})$ e a $90{ }^{\circ} \mathrm{C}(\mathrm{B})$.

[Figure 5: Langmuir adsorption isotherms for $\mathrm{Ag}^{+}$and $\mathrm{Pb}^{2+}$ using $\mathrm{ZrO}, n \mathrm{H}_{2} \mathrm{O}$ prepared at $45^{\circ} \mathrm{C}(\mathrm{A})$ and $\left.90{ }^{\circ} \mathrm{C}(\mathrm{B}).\right]$

Tabela II - Capacidade máxima de adsorção $Q_{0}\left(\mathrm{mg} \mathrm{L}^{-1}\right)$, energia de adsorção $b\left(\mathrm{~L} \mathrm{mg}^{-1}\right)$ e parâmetro de equilíbrio $R_{L}$ do modelo de isoterma de Langmuir para a $\mathrm{Ag}^{+}$e o $\mathrm{Pb}^{2+}$.

[Table II - Maximum adsorption capacity $Q_{0}\left(m g L^{-1}\right)$, adsorption energy $b\left(\mathrm{~L} \mathrm{mg}^{-1}\right)$ and equilibrium parameter $R_{L}$ of Langmuir isotherm model for $\mathrm{Ag}^{+}$and $\left.\mathrm{Pb}^{2+}\right]$.

\begin{tabular}{|c|c|c|c|c|c|c|}
\hline \multirow[t]{2}{*}{ Material } & \multicolumn{2}{|c|}{$Q_{0}\left(\mathrm{mg} \cdot \mathrm{g}^{-1}\right)$} & \multicolumn{2}{|c|}{$b\left(\mathrm{~L} \mathrm{mg}^{-1}\right)$} & \multicolumn{2}{|c|}{$R_{L}$} \\
\hline & $\mathrm{Ag}^{+}$ & $\mathrm{Pb}^{2+}$ & $\mathrm{Ag}^{+}$ & $\mathrm{Pb}^{2+}$ & $\mathrm{Ag}^{+}$ & $\mathrm{Pb}^{2+}$ \\
\hline $\begin{array}{c}\mathrm{Nb}_{2} \mathrm{O}_{5} \cdot \mathrm{nH}_{2} \mathrm{O} \\
\left(45^{\circ} \mathrm{C}\right)\end{array}$ & 108,23 & 218,34 & 0,01073 & 0,00510 & 0,066 & 0,077 \\
\hline $\begin{array}{c}\mathrm{Nb}_{2} \mathrm{O}_{5} \cdot \mathrm{nH}_{2} \mathrm{O} \\
\left(90^{\circ} \mathrm{C}\right)\end{array}$ & 110,01 & 375,94 & 0,00382 & 0,00112 & 0,149 & 0,211 \\
\hline $\begin{array}{c}\mathrm{ZrO}_{2} \cdot \mathrm{nH}_{2} \mathrm{O} \\
\left(45^{\circ} \mathrm{C}\right)\end{array}$ & 9,65 & 4,72 & $-0,00448$ & $-0,00284$ & $-0,197$ & $-0,345$ \\
\hline $\begin{array}{c}\mathrm{ZrO}_{2} \cdot \mathrm{nH}_{2} \mathrm{O} \\
\left(90^{\circ} \mathrm{C}\right)\end{array}$ & 18,91 & 13,49 & 0,00286 & $-0,00097$ & 0,281 & $-0,597$ \\
\hline
\end{tabular}


linear obtida com os valores experimentais de $C_{e}$ e $q_{e}$ para os íons. Observa-se, portanto, pelas Figs. 4 e 5, que os valores experimentais citados, em uma dada região, se ajustam ao modelo de Langmuir. Os valores de correlação linear, para todas as isotermas, são da ordem de 0,999 .

Os parâmetros do modelo de isoterma de Langmuir da remoção de $\mathrm{Ag}^{+}$e de $\mathrm{Pb}^{2+}$ pelos óxidos de nióbio (V) e de zircônio hidratados preparados a 45 e $90^{\circ} \mathrm{C}$ estão apresentados na Tabela II.

Os valores de $Q_{0}\left(\mathrm{mg} \mathrm{g}^{-1}\right)$ do $\mathrm{Nb}_{2} \mathrm{O}_{5} \cdot \mathrm{nH}_{2} \mathrm{O}$ preparado a $45^{\circ} \mathrm{C}$ e a $90^{\circ} \mathrm{C}$ são bem maiores do que aqueles dos $\mathrm{ZrO}_{2} \cdot \mathrm{nH}_{2} \mathrm{O}$ a $45^{\circ} \mathrm{C}$ e a $90^{\circ} \mathrm{C}$, indicando que ambos os óxidos de nióbio hidratados apresentam maior capacidade de trocar íons $\mathrm{Pb}^{2+} \mathrm{e}^{+}$, uma vez que a constante $Q_{0}$ está relacionada com a capacidade de sorção máxima dos íons. Também pela Tabela II, é verificado que os valores de $R_{L}$ para o $\mathrm{Nb}_{2} \mathrm{O}_{5} \cdot \mathrm{nH}_{2} \mathrm{O}$ sintetizado a $45^{\circ} \mathrm{C}$ e a $90{ }^{\circ} \mathrm{C}$ estão entre 0 e 1 , o que indica troca favorável de $\mathrm{Pb}^{2+}{\mathrm{e} \mathrm{Ag}^{+}}^{+}$ nas faixas de concentração estudadas para este material. Para o $\mathrm{ZrO}_{2} \cdot \mathrm{nH}_{2} \mathrm{O}$ sintetizado a $45^{\circ} \mathrm{C}$ e a $90{ }^{\circ} \mathrm{C}$, a adsorção de $\mathrm{Pb}^{2+}$ é desfavorável, visto que a constante $R_{L}$ não se encontra entre 0 e 1 . Observa-se que a troca de $\mathrm{Ag}^{+}$para o óxido de zircônio preparado a $45^{\circ} \mathrm{C}$ também possui valor desfavorável. O óxido de zircônio hidratado preparado a $90{ }^{\circ} \mathrm{C}$ possui troca favorável de $\mathrm{Ag}^{+}$em uma pequena faixa de concentração deste íon. Mesmo tendo troca de $\mathrm{Ag}^{+}$favorável, o $\mathrm{ZrO}_{2} \cdot \mathrm{nH}_{2} \mathrm{O}$ a $90^{\circ} \mathrm{C}$ tem valor de constante $Q_{0}$ muito baixo $\left(18,91 \mathrm{mg} \mathrm{g}^{-1}\right)$ se comparado ao do $\mathrm{Nb}_{2} \mathrm{O}_{5} \cdot \mathrm{nH}_{2} \mathrm{O}$ também preparado a $90^{\circ} \mathrm{C}\left(110,01 \mathrm{mg} \mathrm{g}^{-1}\right)$.

Oxidos de zircônio e de silício hidratados apresentam baixa capacidade de troca iônica, que varia entre 1,0 e 2,0 mmol por grama do trocador [1]. Assim, os resultados desfavoráveis de

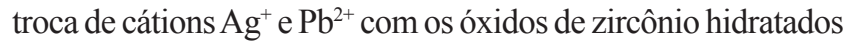
preparados a $45^{\circ} \mathrm{C}$ e a $90{ }^{\circ} \mathrm{C}$, pelo método $\mathrm{PSH}$ também são concordantes com os dados da literatura.

Pode-se observar pelo valor de $Q_{0}$ (Tabela II) que o $\mathrm{Nb}_{2} \mathrm{O}_{5}$. $\mathrm{nH}_{2} \mathrm{O}$ a $90^{\circ} \mathrm{C}$ apresenta melhor troca dos íons $\mathrm{Pb}^{2+}$ que o $\mathrm{Nb}_{2} \mathrm{O}_{5}$. $\mathrm{nH}_{2} \mathrm{O}$ a $45^{\circ} \mathrm{C}$. A adsorção de $\mathrm{Ag}^{+}$, no entanto, é similar para ambos os óxidos de nióbio.

\section{CONCLUSÕES}

A temperatura de decomposição do agente precipitante não acarretou mudanças físicas significativas na preparação dos óxidos de nióbio e de zircônio hidratados estudados. Porém, observaram-se mudanças nas propriedades químicas, como na remoção dos íons prata e íons chumbo para todos os materiais sintetizados.

$\mathrm{O}$ óxido de nióbio hidratado apresentou comportamento

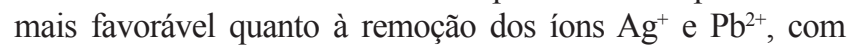
maior seletividade para $\mathrm{Pb}^{2+}$. Isso ocorre provavelmente por características desses materiais que incluem maior grau de hidratação, cristalinidade e espaçamento interlamelar cujos parâmetros favorecem a reação de troca iônica.

\section{NOMENCLATURA}

$C_{e}$ : concentração do metal após atingir o equilíbrio do processo de adsorção $\left(\mathrm{mg} \mathrm{L}^{-1}\right)$. $q_{e}$ : quantidade de íon adsorvido na espécie adsorvente $\left(\mathrm{mg} \mathrm{g}^{-1}\right)$.

$Q_{0}$ : constante relacionada com a capacidade máxima de adsorção do material adsorvente ( $\left.\mathrm{mg} \mathrm{g}^{-1}\right)$.

$R_{L}$ : característica essencial da isoterma de Langmuir (admensional).

\section{AGRADECIMENTOS}

Os autores agradecem o apoio financeiro do CNPq e o Prof. Dr. Paulo Atsushi Suzuki (DEMAR/FAENQUIL) pelo auxílio nas análises dos difratogramas.

\section{REFERÊNCIAS}

[1] L. M. Nunes, C. Airoldi, Quim. Nova 24, 6 (2001) 799.

[2] A. Nilchi, B. Malek, M. G. Maragheh, A. Khanchi, Rad. Phys. Chem. 68, 5 (2003) 837.

[3] G. L. J. P. Silva, M. L. C. P. Silva, T. Caetano, Mater. Res. 5, 2 (2002) 149.

[4] T. Möller, A. Clearfield, R. Harjula, Microporous Mesoporous Mater. 54, 1 (2002) 187.

[5] F. A. Sigoli, A. M. Pires, E. B. Stucchi, M. Jafelicci Jr., M. R. Davolos, Quim. Nova 23, 5 (2000) 627.

[6] N. Baccan, Química Analítica Quantitativa Elementar, Edgard Blücher Ltda., $3^{\text {a }}$ ed., S. Paulo (2004).

[7] M. L. C. P. Silva, G. L. J. P. Silva, E. A. C. Perez, G. V. Tagliaferro, Anais Assoc. Bras. Quim. 50, 2 (2001) 83.

[8] G. V. Tagliaferro, M. L. C. P. Silva, G. L. J. P. Silva, Quim. Nova 28, 2 (2005) 250.

[9] G. V. Tagliaferro, Diss. Mestrado, Faculdade de Engenharia Química de Lorena, Lorena, SP (2003).

[10] D. A. Fungaro, M. G. Silva, Quim. Nova 25, 6B (2002) 1081.

[11] J. D. Lee, J. D. Química Inorgânica não tão Concisa, Edgard Blücher Ltda., 4a ed., S. Paulo (1996).

[12] K. Domen, Y. Ebina, S. Ikeda, A. Tanaka, J. N. Kondo, K. Maruya, Catal. Today 28 (1996) 167.

[13] R. F. Farias, C. Airoldi, J. Solid State Chem. 166 (2002) 277.

[14] J. E. Gardolinski, H. P. Martins F., F. Wypych, Quim. Nova 26, 1 (2003) 30.

[15] J. L. Guimarães, Diss. Mestrado, Universidade Federal do Paraná, PR (2002).

[16] A. S. Prakash, P. V. Kamath, M. S. Hegde, Mater. Res. Bull. 35 (2000) 2189.

[17] I. M. Miguel, Diss. Mestrado, Faculdade de Engenharia Química de Lorena, SP (1995).

[18] M. T. Weller, Inorganic Materials Chemistry, Oxford University Press, New York-Tokio (1994).

[19] Y. Inoue, H. Yamazaki, Y. Kimura, Bull. Chem. Soc. Jpn. 58 (1985) 2481.

[20] Y. Inoue, H. Yamazaki, M. Ikeda, Bull. Chem. Soc. Jpn. 62 (1989) 262.

(Rec. 22/11/2005, Rev. 29/06/2006, Ac. 14/07/2006) 